\title{
Los Derechos Humanos de las mujeres en Europa y América Latina: perspectiva jurisprudencial internacional
}

\section{The Human Rights of Women in Europe and Latin America: an International Case- Law Analysis}

\author{
Carolina Jiménez Sánchez ${ }^{1}$ \\ Universidad de Málaga (España)
}

Recibido: 31-05-18

Aprobado: 22-07-18

\section{Resumen}

El presente artículo analiza la recepción de los Derechos Humanos de las mujeres en los ámbitos regionales del Consejo de Europa y la Organización de Estados Americanos, comprobando su correspondencia con la CEDAW y examinando de manera comparativa la jurisprudencia del Tribunal Europeo de Derechos Humanos y la Corte Interamericana de Derechos Humanos.

Palabras-clave: Derechos Humanos de las Mujeres, América Latina, Europa, Sistemas regionales, CEDAW

\begin{abstract}
This article analyzes the reception of women's human rights in the regional systems of the Council of Europe and the Organization of American States, checking their correspondence with the CEDAW and examining in a comparative way the jurisprudence of the European Court of Human Rights and the Inter-American Court on Human Rights.
\end{abstract}

Key-words: Women's Human Rights, Latin America, Europe, Regional Systems, CEDAW.

\footnotetext{
1(carolina@uma.es). Profesora de Derecho Internacional Público y Relaciones Internacionales de la Universidad de Málaga. El presente artículo se enmarca dentro de la investigación realizada en el proyecto: "Las Respuestas del Derecho Internacional y Europeo a los Nuevos Riesgos y Amenazas Contra la Seguridad Humana" (RASEGUR), Plan Nacional de I+D+I (Ref.: DER2015-65906-P), así como en el Proyecto "Los desafíos de los Derechos Humanos a los nuevos riesgos y amenazas" (EUIN2017-85437).
} 


\section{Las mujeres como sujetos de Derecho Internacional}

La protección del individuo ha sido tradicionalmente un tema marginal para el Derecho Internacional clásico. El denominado "proceso de humanización del Derecho Internacional" fue el medio a través del cual se hizo posible el cambio de orientación y la transformación del Derecho Internacional Público en un cuerpo normativo mucho más cercano a la sociedad. Como afirma CANÇADO TRINDADE "the recognition of the centrality of human rights corresponds to a new ethos of our times. Such process of humanization manifests itself, in my view, as I have been sustaining for years, in all domains of the discipline: the foundations of International Law, its subjects, its new conceptual constructions, the basic considerations of humanity permeating on all its chapter, and the quest for the international rule of law for the realization of justice and maintenance of peace. Such process, in turn, discloses the new jus gentium of our times, the International Law for humankind"2. Y es en el marco de este "proceso de humanización" donde el género puede comenzar a tener cabida en el Derecho Internacional.

Fue la Carta de las Naciones Unidas $^{3}$ la primera en abrir paso a un sistema heterogéneo construido a través de este proceso cuya importancia radica, como advierte Carrillo Salcedo, en la imposición de obligaciones jurídicas en materia de Derechos Humanos tanto a los Estados como a la propia Organización de Naciones Unidas ${ }^{4}$. Estas obligaciones se extienden al cumplimiento del Derecho Internacional de los Derechos Humanos en todas sus manifestaciones.

En una primera fase de desarrollo, la subjetividad de los individuos en el Derecho Internacional era, cuanto menos, limitada y marginal, ni siquiera se vislumbraba un planteamiento de género, que pusiera sobre la mesa la posibilidad de que el Derecho Internacional correspondiera a los individuos con un estatuto jurídico diferenciado según se tratase de hombres o de mujeres. Sin embargo, el estatuto de las personas comenzó a abrirse paso a partir de la aprobación de instrumentos internacionales de vital importancia para el Derecho Internacional Contemporáneo: la Carta de las Naciones Unidas de 1945, como hemos comentado anteriormente, y la Declaración Universal de Derechos Humanos, adoptada por la Asamblea General de Naciones Unidas el 10 de diciembre de $1948^{5}$.

\footnotetext{
${ }^{2}$ Cançado Trindade, A. A., "International Law for Humankind: Towards a New Jus Gentium", 317 R. des Cours, 2005, pp. 536, p.271.

${ }^{3} \mathrm{http} / /$ un.org/es/documents/charter/.

${ }^{4}$ Carrillo Salcedo, J. A., Soberanía del Estado y Derechos Humanos en el Derecho Internacional Contemporáneo, Tecnos, 2001, Madrid, pp. 186, p. 39.

${ }^{5}$ El Derecho Internacional de los Derechos Humanos comienza a cristalizarse con la Declaración Universal de los Derechos Humanos en 1948. Declaración Universal de los Derechos Humanos, de 10 de diciembre de 1948. Accesible en: http://www.un.org/es/documents/udhr/
}

Araucaria. Revista Iberoamericana de Filosofía, Política, Humanidades y Relaciones Internacionales, año 20, $\mathrm{n}^{\circ} 40$ Segundo semestre de 2018. Pp. 483-510. ISSN 1575-6823 e-ISSN 2340-2199 doi: 10.12795/araucaria.2018.i40.22 
La adopción de estos dos textos significó un antes y un después en los Derechos Humanos y, también, en el modo de concebir el Derecho Internacional. Como aprecia MERON "What makes human rights today different from the past is that instead of being only a part of natural law of internal law, human rights have now been accepted as a part of international law".

Respecto a la Carta, es interesante tomar en consideración los comentarios del profesor Charles de Visscher, quien pusiera de manifiesto la relación existente entre el respecto de los Derechos Humanos y las libertades fundamentales en el interior del Estado y el mantenimiento de la paz entre los Estados ${ }^{7}$. Fuera el que fuera el objetivo que se buscase, lo cierto es que con la aprobación de la Carta comienzan a hacerse notorias expresiones como "derechos fundamentales del hombre", que aparece en el Preámbulo del citado texto, "Derechos Humanos", del artículo 55 o "dignidad de la persona humana", que aparece reiteradamente a lo largo del texto. En especial, hemos de subrayar que precisamente en el Preámbulo de la Carta se encuentra una alusión directa a la igualdad entre hombres y mujeres, aunque al principio del párrafo se optara por la expresión "derechos fundamentales del hombre" 8 . Hay que subrayar que, en un primer momento, los textos internacionales suelen recoger el apelativo "del hombre", emulando a la Declaración de los Derechos del Hombre y del Ciudadano $(1789)^{9}$, pero pronto comienza a desaparecer tal denominación, haciéndose más universal el concepto de Derechos Humanos y, al mismo tiempo, más inclusivo. Era una gran contradicción elaborar y adoptar un cuerpo de normas destinada a la humanidad en su conjunto pero que estrechaba su concepto en el propio apelativo restrictivo "del hombre". No es casualidad que aún en estas primeras alusiones a los Derechos Humanos, las mujeres quedaran fuera de toda consideración no sólo específica sino general.

Especial importancia adquiere en el contexto que estudiamos el artículo 1.3 de la Carta que establece entre los propósitos básicos un deber de no discriminación en el que se incluye entre los motivos el sexo ${ }^{10}$. Dejando al margen otros textos internacionales específicos que surgieron con la revolución

\footnotetext{
${ }^{6}$ Meron, T., "International Law in the age of Human Rights", 301 Recueil des Cours, 2003, pp. 489, p. 21.

${ }^{7}$ Carrillo Salcedo, J. A., Soberanía..., op. cit., p. 40.

8 "Nosotros los pueblos de las Naciones Unidas resueltos (...) a reafirmar la fe en los derechos fundamentales del hombre, en la dignidad y el valor de la persona humana, en la igualdad de derechos de hombres y mujeres (...) ’”, Preámbulo de la Carta de las Naciones Unidas, 26 de junio de 1945, San Francisco. Accesible en: https://www.un.org/spanish/aboutun/charter.htm.

9 Declaración de los Derechos del Hombre y del Ciudadano, aprobada por la Asamblea General Constituyente francesa el 26 de agosto de 1789. Accesible en: http://www.juridicas.unam.mx/publica/ librev/rev/derhum/cont/30/pr/pr23.pdf

${ }^{10}$ El artículo 1.3 de la Carta incluye como propósitos de las Naciones Unidas "Realizar la cooperación internacional en la solución de problemas internacionales de carácter económico, social, cultural o humanitario, y en el desarrollo y estímulo del respeto a los derechos humanos y a las libertades fundamentales de todos, sin hacer distinción por motivos de raza, sexo, idioma o religión (...) '. Carta de las Naciones Unidas, op. cit.
} 
francesa (que veremos más adelante), esta es la primera alusión al sexo en el campo de los Derechos Humanos a nivel universal y general, junto con la ya comentada igualdad entre hombres y mujeres que se establece en el Preámbulo. A ellas, habría que sumar también el artículo 76 de la Carta, que establece el deber de no discriminar en el respeto a los Derechos Humanos, incluyendo también el sexo como uno de los motivos tasados. El artículo 76 establece que la Administración Fiduciaria debe: "promover el respeto a los Derechos Humanos y libertades fundamentales de todos, sin hacer distinción por motivos de raza, sexo, idioma o religión”.

En este punto parece claro que los individuos, tanto hombres como mujeres, están dotados de derechos básicos y universales, tanto en la esfera nacional como en la internacional. No obstante, hay que matizar que su subjetividad sigue siendo muy marginal, ya que el lugar tradicional de la persona en la Comunidad Internacional ${ }^{11}$ es actuar a través del cauce de los Estados $^{12}$.

Así, el Derecho Internacional de los Derechos Humanos (en adelante, $\mathrm{DIDH})$ ha ido construyéndose a través de normas convencionales, en su mayoría, creadas a partir de la segunda mitad del siglo XX. El amplio desarrollo experimentado por esta rama del Derecho Internacional ha hecho posible que las normas convencionales adoptadas no sólo hayan sido de carácter general, sino que se ha atendido a los grupos considerados específicos -dependiendo de cuál fuese el foco de atención en cada época-, adoptando instrumentos convencionales protectores de derechos concretos cuyos destinatarios se limitan a los miembros del grupo.

Hay que advertir que durante los últimos 50 años, los principios que inspiran el DIDH así como el Derecho Internacional General, han resultado modificados debido a la reivindicación de igualdad entre hombres y mujeres ${ }^{13}$, que comenzaba con las ya comentadas alusiones a la igualdad en el interior de la Carta de Naciones Unidas, primer texto internacional que establece como principio la no discriminación por motivos de $\operatorname{sexo}^{14}$.

11 A lo largo de esta investigación se usará el término Comunidad Internacional y no el de Sociedad Internacional, por entender que priman los elementos comunitarios de los sujetos que la componen, siguiendo la diferenciación delineada por R. J., Dupuy, (Vid., Dupuy, R. J., “Communauté Internationale et Disparités de Développement”, R. Des Cours, $\mathrm{n}^{\circ}$ 165, 1979, IV. Además, el término Comunidad Internacional ha sido incluido en varias Resoluciones de la Asamblea General, entre las que destaca la 2625 (XXV), de 4 de noviembre de 1970. Sobre la noción de Comunidad Internacional Vid. también: Reeves, J. S., "La Communauté Internationale", R. Des Cours, no 3, 1934; Carrillo Salcedo, J. A., "Influencia en la noción de Comunidad Internacional en la naturaleza del Derecho Internacional Público", en Pacis Artes: Obra homenaje al profesor D. Julio González Campos, vol. 1, Eurolex, Madrid, 2005, pp. 51-142; Tomuschat, C., "La Comunidad Internacional", en La constitucionalización de la Comunidad Internacional, Tirant lo Blanch, Valencia, 2010, pp. 93-119.

${ }^{12}$ Carrillo Salcedo, J. A., Soberanía del Estado..., op. cit., p. 36.

${ }^{13}$ Robertson, A. H., "Humanitarian Law and Human Rights", en Studies and essays on international humanitarian law and Red Cross principles in honour of Jean Pictet, SWINARSKI, C (ed.), CICR/ Martinus, Ginebra/La Haya, 1984, pp. 793-802.

${ }^{14}$ Charlesworht, H.; Chinkin, C., The Boundaries of International Law. A feminist analysis, Meland 
A partir de este primer eslabón se ha ido construyendo una sub-disciplina dentro del ámbito de los Derechos Humanos, que algunos sectores doctrinales han convenido llamar "Derechos Humanos de la mujer"15 o "enfoque feminista de los derechos fundamentales" ${ }^{16}$, con la adopción de textos internacionales protectores de los Derechos Humanos específicos de las mujeres y niñas, pero antes de ello existían algunas alusiones directas e indirectas en los textos protectores de Derechos Humanos a nivel universal y general.

El primer instrumento jurídico internacional sobre protección de Derechos Humanos elaborado por una Organización Internacional a nivel universal es la Declaración Universal de Derechos Humanos ${ }^{17}$. Hay que señalar, igualmente, que Organización de Naciones Unidas creó en 1946 dentro de la Comisión de Derechos Humanos, la Comisión sobre la Condición Social y Jurídica de la Mujer, ambas presididas por Eleenor Roosvelt ${ }^{18}$, encargada, entre otras cosas, de la asunción de un lenguaje no sexista en la Declaración.

Sin embargo, es precisamente su universalidad lo que actualmente se encuentra en tela de juicio ${ }^{19}$. Así, mientras la posición llamada universalista defiende que todos los seres humanos tienen los mismos derechos inalienables y que, por tanto, la Comunidad Internacional está legitimada para juzgar los patrones internacionales relativos a los Derechos Humanos, la posición

Schill Studies in International Law, Juis Publishing, Manchester University Press, Manchester, 2000, pp. 414, p. 213.

${ }^{15}$ Este enfoque toma importancia a partir de la Plataforma de Acción de Beijing en 1995. Al respecto vid., Los derechos humanos de la mujer, Nota informativa número 9, Mujer 2000, Igualdad entre los géneros, desarrollo y paz para el siglo XXI., Sección de Desarrollo y Derechos Humanos, Sección de Información Pública de Naciones Unidas. Accesible en: http://www.un.org/spanish/ conferences/Beijing/fs9.htm.

${ }^{16}$ Barranco Avilés, Ma . del C., "El enfoque feminista de los derechos fundamentales desde la perspectiva de género", en Género y Derechos Fundamentales, (Monereo Atienza, C.; Monereo Pérez, J. L., coords.), Granada, Comares, pp. 49-85, p. 49.

${ }^{17}$ Es interesante señalar que el primer nombre dado a este texto fue Declaración Universal de Derechos del Hombre, denominación que a posterior y con gran acierto fue cambiada por la que hoy conocemos, a través de la Resolución 548 (VI) de la Asamblea General de Naciones Unidas, de 5 de febrero de 1952.

${ }^{18}$ Eleanor Roosvelt, pese a ser una figura poco estudiada dentro del feminismo, ha sido la mayor precursora de los derechos de las mujeres dentro de las Naciones Unidas. Al respecto Vid.: Glendom, M. M., A World Made New. Eleanor Roosvelt and the Universal Declaration of Human Rights, Random House, Nueva York, 2001, pp. 333.

${ }^{19}$ Vid, entre otros: Carrillo Salcedo, J. A., "La Declaración Universal de Derechos Humanos. ¿Es universal?, Tiempo de Paz, n 48, 1998, pp. 11-18; Blanc Altemir, A., "Universalidad, indivisibilidad e interdependencia de los derechos humanos a los cincuenta años de la Declaración Universal", en $L a$ protección internacional de los Derechos Humanos a cincuenta años de la Declaración Universal, (Blanc Altemir, A. Coord.), Tecnos, 2001, Madrid, pp. 13-36; Cianciardo, J., "Para siempre, para todos: los desafíos de la universalidad a sesenta años de 1948, Persona y Derecho, vol. 59, 2008, 19-55; Nair, S., "Universalidad, diversidad y conflictos políticos", en Los desafios de los derechos humanos hoy, De Assís, R.; Bondía, D.; Maza, E, (Coords.), Dyckinson, 2007, Madrid, pp. 145-153; Barreiro Carril, B., "Un análisis de la relación entre la diversidad cultural y la universalidad de los derechos humanos. Especial referencia a algunos elementos novedosos aportados por la convención de la UNESCO para la diversidad cultural", Revista de Derecho Migratorio y Extranjería, n² 27, 2011, pp. 61-79.

Araucaria. Revista Iberoamericana de Filosofia, Política, Humanidades y Relaciones Internacionales, año $20, \mathrm{n}^{\circ} 40$ Segundo semestre de 2018. Pp. 483-510. ISSN 1575-6823 e-ISSN 2340-2199 doi: 10.12795/araucaria.2018.i40.22 
relativista argumenta que no pueden existir críticas externas válidas de otras culturas $^{20}$, ya que no existe un sistema de análisis transcultural completamente objetivo y desligado de patrones predeterminados. Más allá de la polémica, hay que subrayar que la importancia de la Declaración Universal de Derechos Humanos ha sido supra-occidental, y ha evitado el peligroso vacío del abismo relativista con un estándar de mínimos. Además, si nos detenemos a considerar el aspecto puramente jurídico-internacional de la Declaración, hay que tener en cuenta que se ha postulado su carácter de norma de ius cogens ${ }^{21}$, represente o no una perspectiva global de los Derechos Humanos.

El artículo 1 expresa la idea general sobre la que se nutre todo el texto, y que tiene una importancia vital ${ }^{22}$ : "Todos los seres humanos nacen libren e iguales en dignidad y derechos y,
dotados como están de razón y conciencia, deben comportarse fraternalmente
los unos con los otros".

Por su parte, el artículo 2, que establece la prohibición de discriminación:

"Toda persona tiene los derechos y libertades proclamados en esta Declaración, sin distinción alguna de raza, color, sexo, idioma, religión, opinión pública o de cualquier otra índole, origen nacional y social, posición económica, nacimiento o cualquier otra condición".

Más allá de la protección de Derechos Humanos universales y del establecimiento de una igualdad general y formal, la Declaración contiene alguna disposición específica para las mujeres, aunque se trate de conexiones realizadas en relación a patrones de género tradicionales, En este sentido, el artículo 16 en cuanto a los derechos matrimoniales establece que:

\begin{abstract}
"los hombres y las mujeres, a partir de la edad núbil, tienen derecho, sin restricción alguna por motivos de raza, nacionalidad o religión, a casarse y fundar una familia; y disfrutarán de iguales derechos en cuanto al matrimonio, durante el matrimonio y en caso de disolución del matrimonio. Sólo mediante libre y pleno consentimiento de los futuros esposos podrá contraerse matrimonio"
\end{abstract}

\footnotetext{
${ }^{20}$ Maquieira, V., "Mujeres, globalización y derechos humanos", en Mujeres, globalización y Derechos Humanos, Maqueieira, V. (Ed.), pp. 33-87, p. 68, 1ª edición, Ediciones Cátedra, 2006, Valencia, pp. 405.

${ }^{21}$ Acosta López, J. I.; Luque Vallejo, A M., "Declaración Universal de Derechos Humanos, ¿norma de ius cogens?", International Law: Revista colombiana de Derecho Internacional, n 12, 2008, pp. 13-34.

22 Entrando en su contenido, la división adoptada por CASSIN muestra cuatro pilares fundamentales de derechos. En primer lugar, derechos y libertades de orden personal (arts. 3 a 11), seguidos de los derechos del individuo relacionados con los grupos de que forma parte (arts. 12 a 17). El tercer pilar estaría formado por las libertades y derechos políticos (arts. 18 a 21) y el último de los cuatro pilares sería el referente a los derechos económicos, sociales y culturales (arts. 22 a 27). Todo ello edificado sobre igualdad inherente de todos los seres humanos. Vid. Cassin, R., "La Déclaration Universelle et la mise en oeuvre des Droits de 1'Homme", RCADI, 1951-II, vol. 79, pp. 239-367.
} 
Al margen de lo relativo a derechos matrimoniales que acabamos de ver, la Declaración no contiene otros preceptos específicos sobre las mujeres.

Posteriormente, el Pacto Internacional de Derechos Civiles y Políticos ${ }^{23}$ y el Pacto Internacional de Derechos Económicos, Sociales y Culturales ${ }^{24}$, son los instrumentos que incorporan artículos relativos a los derechos inherentes a la familia y al matrimonio (art. 23), con bastante influencia de la Declaración Universal de Derechos Humanos, pero sin disposiciones que contengan algún otro tipo de protección específicas de los derechos de las mujeres.

Aunque otros textos internacionales de carácter general han hecho referencias a derechos específicos para las mujeres, es cierto que será con esta Carta Internacional de Derechos Humanos ${ }^{25}$ con la que se abra paso a la posibilidad de considerar a las mujeres como un grupo con la necesidad de blindar una serie de derechos concretos que resultan afectados en todas las sociedades. Hoy en día, los Derechos Humanos de las mujeres encuentran su fundamento, no sólo en las convenciones generales, sino en otras específicas que se han encargado de catalogar los derechos que correspondían a las mujeres por el hecho de serlo. Desde la reivindicativa Carta de Derechos de la Mujer y la Ciudadana de Olympe de Gougois en 1791, pasando por los diferentes Convenios sobre la supresión de la entonces llamada "trata de blancas" en $1902,1910,1921$ y $1933^{26}$. Es cierto que, si bien éstos carecían totalmente de una perspectiva de género, se ocupaban de un tipo de violencia que se da desproporcionadamente hacia las mujeres. Ya en los años cincuenta, surgen convenciones con un calado más social, como la Convención sobre los Derechos Políticos de la Mujer, de $1952^{27}$, y la tan necesaria Convención sobre la nacionalidad de la mujer casada de $1956^{28}$. Ya en 1967 destaca la primera declaración de carácter universal sobre los derechos humanos de las mujeres, la Declaración sobre la eliminación de toda discriminación contra las mujeres, aprobada por la Asamblea General de las Naciones Unidas. Ésta comenzaría a reorientar el curso de las políticas, acciones y estrategias de la Organización

${ }^{23}$ Pacto Internacional de Derechos Civiles y Políticos. Nueva York, 16 de diciembre de 1966. Torres Ugena, N., Textos normativos de Derecho Internacional Público, $10{ }^{a}$ edición, ThomsonCivitas, Textos básicos, 2006, pp. 1982, p. 547.

24 Pacto Internacional de Derechos Económicos, Sociales y Culturales. Nueva York, 16 de diciembre de 1966. Torres Ugena, N., Textos normativos..., op. cit., p.. 572.

${ }_{25}$ Se denomina Carta Internacional de Derechos Humanos a la suma entre la Declaración Universal de Derechos Humanos y los Pactos Internacionales de 1966.

${ }^{26}$ Son los siguientes: Acuerdo Internacional para la supresión del tráfico de blancas, hecho en París, 18 de mayo de 1902; Acuerdo Internacional para la supresión del tráfico de blancas, hecho en París, 4 de mayo de 1910; Convención Internacional para la supresión del tráfico de mujeres y niños, hecha en Ginebra, 30 de septiembre de 1921; Convención Internacional para la supresión del tráfico de mujeres mayores de edad, hecha en Ginebra, 11 de octubre de 1933.

${ }_{27}$ Convención sobre los Derechos Políticos de la Mujer, aprobada por la Resolución 640 (VII) de la Asamblea General de las Naciones Unidas, de 20 de diciembre de 1952.

${ }^{28}$ Convención sobre la Nacionalidad de mujer casada, aprobada por la Resolución 1040 (XI) de la Asamblea General de las Naciones Unidas, de 29 de enero de 1957.

Araucaria. Revista Iberoamericana de Filosofia, Política, Humanidades y Relaciones Internacionales, año 20, $\mathrm{n}^{\circ} 40$. Segundo semestre de 2018. Pp. 483-510. ISSN 1575-6823 e-ISSN 2340-2199 doi: 10.12795/araucaria.2018.i40.22 
hacia el avance de las mujeres poniendo la semilla de las venideras Conferencias Mundiales de la Mujer. En 1979, inspirada por esta declaración, se adopta la Convención para la Eliminación de toda forma de discriminación contra las Mujeres, la CEDAW. Esta Carta Magna de los derechos de las mujeres entraba en vigor en 1981 tras alcanzar las veinte primeras ratificaciones, incorporando por primera vez en un tratado un catálogo completo de Derechos Humanos referidos a las mujeres y niñas de todo el planeta.

Esta universalidad había de ser recogida no sólo por los Estados parte, sino por todos los sistemas regionales de protección de Derechos Humanos, siendo una importante cuestión la de examinar cuál es la relación e integración entre los derechos humanos de las mujeres universalmente declarados y, aquellos que los diferentes ámbitos regionales han convenido en recoger y desarrollar, aspecto sobre el que se centrará el siguiente análisis.

\section{La interrelación de los Derechos Humanos de las mujeres en el ámbito universal y regional}

A continuación se analizará comparativamente la protección de los derechos humanos de las mujeres en los ámbitos regionales europeo y americano, examinando la labor de la OEA y el Consejo de Europa, comprobando también la correlación de sus normas con la Convención para la Eliminación de todas las formas de discriminación contra la mujer (CEDAW), de ámbito universal.

La CEDAW es precisamente uno de los tratados internacionales de Derechos humanos más ratificado del planeta, con un total de 186 ratificaciones de 189 Estados parte ${ }^{29}$. Como hemos puesto de relieve, tras su adopción en el año 1979 (tras más de treinta años de trabajo de la Comisión para la Condición Jurídica y Social de la Mujer) se convirtió en el primer catálogo de derechos humanos de las mujeres a nivel universal y, por tanto, un espejo en el que mirarse para los ámbitos regionales que quisieran convertirse en estandartes de la protección de los derechos de las mujeres. Además de definir el concepto de "discriminación sobre la mujer" y ofrecer una visión amplia de "derechos humanos" la CEDAW hace hincapié en la necesidad de modificar los patrones socioculturales de hombres y mujeres para conseguir eliminar los prejuicios de género ${ }^{30}$. Pese a la gran acogida obtenida, la Convención ha sido objeto de numerosas y polémicas reservas a su articulado por parte de un gran número de Estados $^{31}$, por lo que ha sido de gran utilidad la creación en el mismo convenio

${ }^{29}$ Los tres Estados que aún faltan por ratificar el texto son: Palau, República de Tanzania y Estados Unidos de Norteamérica. Vid. https://reaties.un.org/Pages/ViewDetails.aspx?src=TREATY\&mtdsg no $=\mathrm{IV}-8 \&$ chapter $=4 \&$ lang $=$ en.

30 Art. 5 de la CEDAW.

31 Vid. Martín Martínez, M. y Jiménez Sánchez, C., "La protección internacional de los derechos 
de un órgano de control, el Comité que, además, ampliaba sus funciones a través del Protocolo Facultativo adoptado en $1999^{32}$.

Décadas antes de que se adoptara la CEDAW, algunos ámbitos regionales destacaban por su liderazgo en el desarrollo y promoción de los Derechos Humanos y Libertades Fundamentales. Sólo dos años después de la DUDH, en el marco de la "gran Europa" se adoptaba el Convenio Europeo de Derecho Humanos (CEDH), texto en el que ya se encontraba inserta la cláusula de no discriminación que incluía el sexo entre los motivos tasados (art. 14), lo que constituye la mínima protección exigible a un catálogo de derechos humanos nacido en 1950: en el texto no se consagra la igualdad entre hombres y mujeres, sino que simplemente prohíbe la discriminación por motivos de sexo. Alusiones posteriores a la igualdad en algunos de los protocolos adicionales al CEDH completan algo más el marco jurídico de la igualdad entre hombres y mujeres, aunque de manera francamente insuficiente. Entre ellos, el Protocolo Adicional $\mathrm{n}^{\mathrm{o}} 7$ (1988) establece la igualdad jurídica de los cónyuges en el matrimonio, casi una década después de la mucho más ambiciosa CEDAW. También hay que destacar el Protocolo Adicional $n^{\circ} 12$ (2000), que reitera la prohibición general de no discriminación ampliando tibiamente su conceptualización hacia una lectura más moderna y acorde con textos como la CEDAW, según su propio Informe Explicativo ${ }^{33}$. Sin embargo, el Consejo de Europa perdió con este Protocolo la oportunidad de adoptar un texto específico sobre los Derechos Humanos de las mujeres para conformarse con legitimar las acciones positivas (de manera indirecta) promoviendo la igualdad desde el Preámbulo de este Protocolo $n^{\circ} 12^{34}$.

La jurisprudencia del TEDH ya ha puesto de manifiesto en diferentes ocasiones su interpretación sobre la cláusula general de no discriminación, teniendo muy en cuenta y de manera reiterada la diferencia que puede existir entre la desigualdad de trato y la discriminación, e insistiendo que en que ambas no siempre coinciden ${ }^{35}$. Además, la doctrina del margen de apreciación a los Estados hace que, en definitiva sea necesario desarrollar de manera más específica los Derechos Humanos de las mujeres en el marco del

humanos de las mujeres: una visión desde la multiculturalidad y la perspectiva de género", en Diversidad Cultural, Género y Derecho, (Laurenzo Copelo, P.; Durán Muñoz, R., Coords.), Tirant lo Blanch, Valencia, 2013, pp. 271-307.

${ }^{32}$ Protocolo Facultativo de la Convención sobre la eliminación de todas las formas de discriminación contra la mujer, adoptado por la Asamblea General en su resolución A/54/4 de 6 de octubre de 1999.

${ }^{33}$ Explanatory Report to the Protocol no. 12 to the Convention for the Protection of Human Rights and Fundamental Freedoms, European Treaty Series n ${ }^{\circ}$ 177, Council of Europe, Rome, 4.XI.2000.

${ }^{34}$ En el Preámbulo del Protocolo Adicional n 12 se expresa que "el principio de no discriminación no impide a los Estados Partes tomar medidas para promover una igualdad plena y efectiva, siempre que respondan a una justificación objetiva y razonable".

${ }^{35}$ Aunque es un criterio jurisprudencial constante en la jurisprudencia del TEDH, puede verse muy claramente en la Sentencia relativa al asunto Abdulaziz, Cabales y Balkandali c. el Reino Unido, $\mathrm{n}^{\mathrm{o}}$ 21702/93. 
Consejo de Europa ${ }^{36}$ para conseguir su protección efectiva, asunto en el que profundizaremos más adelante.

El otro ámbito regional que ha destacado por su sistema de protección de los Derechos Humanos es el americano. La Convención Americana de Derechos Humanos (Pacto de San José) establece en su artículo primero una clausula paralela a la del CEDH de no discriminación entre cuyos motivos tasados se encuentra el sexo, así como la igualdad de los cónyuges en el artículo 17. Pero igualmente ha desarrollado los Derechos Humanos de las mujeres en textos específicos, incluso con fecha muy anterior al propio Pacto de San José, práctica que sólo encuentra analogía en los convenios específicos sobre trata de blancas o las convenciones de calado más social de los años 50 del pasado siglo en el ámbito universal. Hay que subrayar la adopción de dos textos: la Convención Interamericana sobre la concesión de los derechos políticos a la mujer $^{37}$ y la Convención Interamericana sobre la concesión de los derechos civiles a la mujer ${ }^{38}$, ambas de 1948.

Es cierto que la gran recepción universal de la CEDAW ha hecho posible su consagración como Carta Magna de los derechos de las mujeres, siendo así considerada en todos los ámbitos regionales. Sin embargo, esto no ha supuesto en los ámbitos europeo y americano la adopción de catálogos de Derechos Humanos de las mujeres análogos a la misma, sino que el asunto ha querido solventarse con la inclusión de algunos de los preceptos generales de igualdad y no discriminación en textos de alcance general, (sin contar los convenios anteriores y específicos surgido en el ámbito interamericano).

No obstante, los sistemas regionales protectores de derechos humanos de las regiones analizadas, sí han tomado en consideración un forma específica de discriminación hacia las mujeres, que podemos confirmar como la de mayor gravedad: la violencia. Algo alejada del enfoque tradicional de los catálogos de Derechos Humanos, la violencia contra las mujeres ha sido objeto de preocupación en diferentes ramas del propio Derecho Internacional, como el Derecho Internacional Penal o el Derecho Internacional Humanitario, permaneciendo al margen en los Derechos Humanos que reforzaban la enunciación positiva de derechos y las prohibiciones de discriminación.

En este sentido, será la OEA la primera en ofrecer una atención específica a la violencia que se ejerce contra las mujeres en un texto jurídico vinculante. Catorce años después de la entrada en vigor de la CEDAW, se adoptaba en el seno de la OEA la Convención Interamericana para prevenir, sancionar y erradicar la violencia contra la mujer (Convención de Belem do Para) ${ }^{39}$,

\footnotetext{
${ }^{36}$ Sobre el margen de apreciación véase por ejemplo véase, por ejemplo, la Sentencia de 28 de noviembre de 1984 sobre el asunto Rasmussen c. Dinamarca, Serie A, n. ${ }^{\circ}$ 87, apartado 40.

${ }^{37}$ Se establece el sufragio femenino activo y pasivo, con la reserva de Honduras.

${ }^{38}$ Se establece la equiparación de derechos a hombres y mujeres en el ámbito civil.

39 Convención Interamericana para prevenir, sancionar y erradicar la violencia contra la mujer
} 
incluyendo a partir del año 2004 un mecanismo de evaluación y seguimiento (MESECVI), con la participación de un comité de expertos, los Estados parte y la sociedad civil. En la actualidad cuenta con la ratificación de 32 Estados de los 34 Estados miembros de la Organización ${ }^{40}$.

Por su parte, el Consejo de Europa esperaría hasta el año 2011 para aprobar su Convenio sobre prevención y lucha contra la violencia contra las mujeres y la violencia doméstica (Convenio de Estambul), entrando éste en vigor en el año 2014. La elaboración del texto corrió a cargo de un comité de expertos denominado CAHVIO (Ad Hoc Committee for preventing and combating violence against women and domestic violence) a partir del año 2008. Algunos años antes, ya en 2002, el Comité de Ministros del Consejo de Europa aprobó la Recomendación (2002) 5, de protección de las mujeres contra la violencia ${ }^{41}$ y la Asamblea Parlamentaria también aprobaría una serie de recomendaciones sobre este tipo de violencia a lo largo de esta década. Hasta la fecha, 30 Estados miembros del Consejo de Europa han ratificado la Convención, 15 sólo han depositado el instrumento de firma ${ }^{42}$. Por otro lado, Azerbaiyán y Rusia han quedado al margen del mismo, al igual que los Estados observadores ${ }^{43}$.

En este escenario, los ámbitos regionales americano y europeo han acogido en parte la necesidad de reforzar los mecanismos de derechos humanos procediendo a su integración universal/regional en claro seguimiento al espíritu de la CEDAW. No obstante, hay que subrayar que ambas convenciones responden a un objetivo concreto como es la violencia basada en el género y, por tanto, no podemos considerarlos catálogos de derechos humanos de las mujeres, sino como instrumentos específicos para hacer frente a este tipo de violencia.

Partiendo de la base de que la CEDAW es un catálogo universal de Derechos Humanos específicos y, los textos regionales de la OEA y el Consejo de Europa no tienen dicho objeto sino abordar el reto concreto de la violencia sobre las mujeres, hay que tener en cuenta que se parte de enfoques de Derechos Humanos diferentes pero absolutamente complementarios. Tanto es así que, a su vez, en el ámbito universal el Comité de la CEDAW, en su labor de elaborar recomendaciones generales, adoptó en 1989 la Recomendación General n 12 sobre Violencia contra la Mujer ${ }^{44} \mathrm{y}$, posteriormente en 1992 la Recomendación

(Convención de Belem do Para), de 14 de agosto de 1995.

${ }^{40}$ Excluyendo a Canadá y Estados Unidos de Norteamérica.

${ }^{41}$ Protección de las mujeres contra la violencia, Recomendación Rec (2002) 5 adoptada por el Comité de Ministros del Consejo de Europa el 30 de abril de 2002.

${ }^{42}$ Estos 15 son: Armenia, Bulgaria, Croacia, República Checa, Grecia, Hungría, Irlanda, Letonia, Liechtenstein, Lituania, Luxemburgo, Moldavia, Eslovaquia, Ucrania y Reino Unido. También ha firmado el Convenio la Unión Europea, hasta el momento sin ratificación.

${ }^{43}$ Canadá, Estados Unidos de Norteamérica, la Santa Sede, Japón y México.

${ }^{44}$ Recomendación General no 12 (Sexto período de sesiones, 1987) adoptada por el Comité para la eliminación de la Discriminación de la Mujer. Accesible en: http://www.un.org/womenwatch/daw/ cedaw/recommendations/recomm-sp.htm\#recom12.

Araucaria. Revista Iberoamericana de Filosofia, Politica, Humanidades y Relaciones Internacionales, año 20, $\mathrm{n}^{\circ} 40$. Segundo semestre de 2018. Pp. 483-510. ISSN 1575-6823 e-ISSN 2340-2199 doi: 10.12795/araucaria.2018.i40.22 
General n ${ }^{0} 19$ también sobre Violencia sobre la Mujer5, (en adelante, RG19) que viene a completar la perspectiva de la Convención. La conexión entre los conceptos de "discriminación" y de "violencia" en el marco de los Derechos Humanos de las mujeres resulta altamente interesante planteado desde una perspectiva de desarrollo progresivo de este cuerpo normativo. Pese a que la violencia en sí misma no se incorpora a los catálogos de Derechos Humanos, sí hay que reiterar que la violación de algunos artículos insertos en la CEDAW y otros textos implican necesariamente el ejercicio de la violencia. Así lo pone de manifiesto la RG19 al expresar que "la violencia contra la mujer puede contravenir disposiciones concretas de la Convención, independientemente en ellas se mencione expresamente la violencia o no". Estos derechos que se verían afectados al usarse "violencia" contra las mujeres serían: el derecho a la vida, el derecho a no ser sometido a torturas, tratos o penas inhumanas o degradantes, el derecho al nivel más alto de salud física y mental o de manera más general el derecho a no ser discriminado. La RG19 conecta la violencia a diferentes artículos de la CEDAW, como son el 3, 5, 6, 10, 11, 12, 14 y 16. Así pues la violencia sería el resultado de una violación de estos artículos, y por tanto, dentro de la perspectiva de los Derechos Humanos, la protección de los mismos implica la protección contra la violencia. En efecto, el ejercicio de violencia sobre las mujeres, tiene una clara afectación sobre la seguridad humana mundial. Según la OMS un tercio de las mujeres en el mundo sufre algún tipo de violencia basada en el género, y esto es algo que ha pasado frecuentemente inadvertido por el régimen internacional de Derechos Humanos general, y naturalizado o invisibilizado por las relaciones internacionales convencionales $^{46}$.

La alta sistematización de las recomendaciones generales del Comité de la CEDAW sobre la violencia contra la mujer tiene mucho que ver con la propuesta que existió en los años 90 de elaborar un texto específico sobre violencia basada en el género, idea que finalmente fue descartada por el Comisión sobre la condición jurídica y social de la mujer ${ }^{47}$. Al mismo tiempo, esta integración entre el concepto de violencia basada en el género y Derechos Humanos de las mujeres viene a completar un hueco existente en el Derecho Internacional de los Derechos Humanos como es la ausencia hasta entonces de prohibición directa y expresa al ejercicio de violencia sobre las mujeres.

${ }^{45}$ Recomendación General no 19 (Onceavo período de sesiones, 1992), adoptada por el Comité para la eliminación de la Discriminación de la mujer. Accesible en: http://www.un.org/womenwatch/ daw/cedaw/recommendations/recomm-sp.htm\#recom19

46 Brysk, A., "Introducción: violencia de género y Relaciones Internacionales", Revista CIBOD $D^{\prime}$ afers Interacionals, $\mathrm{n}^{\circ} 117,2017$, pp. 7-28, p. 8.

47 Simonovic, D., "Global and Regional Standarts on Violence Against Women: The Evolution and Sinergy of the CEDAW and Istambul Conventions", Human Rights Quarterly, 36 (2014), pp. 590-606, p. 600.

Araucaria. Revista Iberoamericana de Filosofía, Política, Humanidades y Relaciones Internacionales, año 20, $\mathrm{n}^{\circ} 40$. Segundo semestre de 2018. Pp. 483-510. ISSN 1575-6823 e-ISSN 2340-2199 doi: 10.12795/araucaria.2018.i40.22 
Pese al diferente enfoque adoptado en los textos regionales citados, es interesante comparar el grado de integración del espíritu y finalidad de la CEDAW y su RG19, para así examinar si se ha producido realmente una recepción de los principios inspiradores de los Derechos Humanos de las mujeres a nivel universal, lo que se pretende facilitar a través de la siguiente tabla comparativa:

\begin{tabular}{|c|c|c|c|}
\hline Convención & Belem do Para & Convenio de Estambul & CEDAW+ RG19 \\
\hline Objetivo & $\begin{array}{l}\text { Prevenir, sancionar y } \\
\text { erradicar la violencia } \\
\text { contra la mujer }\end{array}$ & $\begin{array}{l}\text { Prevenir y luchar } \\
\text { contra violencia } \\
\text { contra las mujeres } \\
\text { (+ violencia doméstica) }\end{array}$ & $\begin{array}{l}\text { Eliminación } \\
\text { todas formas } \\
\text { discriminación } \\
\text { contra la mujer }\end{array}$ \\
\hline Preámbulo & $\begin{array}{l}\text { La violencia contra } \\
\text { las mujeres es } \\
\text { una violación de } \\
\text { DDHH producto } \\
\text { de relaciones de } \\
\text { poder históricas }\end{array}$ & $\begin{array}{l}\text { Aspira a crear una } \\
\text { Europa libre de } \\
\text { violencia contra las } \\
\text { mujeres y doméstica }\end{array}$ & $\begin{array}{l}\text { Incorporar la } \\
\text { mitad femenina } \\
\text { de la humanidad } \\
\text { a los tratados } \\
\text { internacional } \\
\text { de DDHH }\end{array}$ \\
\hline $\begin{array}{l}\text { Definición } \\
\text { "Violencia } \\
\text { contra } \\
\text { la mujer" }\end{array}$ & $\begin{array}{l}\text { Acción o conducta, } \\
\text { basada en el género, } \\
\text { que cause muerte, } \\
\text { daño o sufrimiento } \\
\text { físico, sexual o } \\
\text { psicológico a la } \\
\text { mujer, tanto en el } \\
\text { ámbito público } \\
\text { como en el privado }\end{array}$ & $\begin{array}{l}\text { Actos de violencia } \\
\text { basados en el género } \\
\text { que implican o } \\
\text { pueden implicar para } \\
\text { las mujeres daños } \\
\text { o sufrimientos de } \\
\text { naturaleza física, } \\
\text { sexual, psicológica o } \\
\text { económica, incluidas } \\
\text { las amenazas de } \\
\text { realizar dichos actos, } \\
\text { la coacción o la } \\
\text { privación arbitraria } \\
\text { de libertad, en la vida } \\
\text { pública o privada }\end{array}$ & $\begin{array}{l}\text { Recomendación } \\
\text { General nº } 19 \text { : } \\
\text { conexión con } \\
\text { artículos de } \\
\text { la CEDAW }\end{array}$ \\
\hline $\begin{array}{l}\text { Incluye } \\
\text { catálogo } \\
\text { general de } \\
\text { DDHH }\end{array}$ & $\begin{array}{l}\text { Arts. 3-6, cláusula } \\
\text { abierta }\end{array}$ & No & $\begin{array}{l}\text { Sí, catálogo } \\
\text { completo }\end{array}$ \\
\hline $\begin{array}{l}\text { Diligencia } \\
\text { debida } \\
\text { (Estados) }\end{array}$ & Sí. Artículo 7 & $\begin{array}{l}\text { Sí: obligaciones de } \\
\text { prevención, protección, } \\
\text { apoyo e investigación }\end{array}$ & $\begin{array}{l}\text { Sí, en } \\
\text { Recomendación } \\
\text { General no } 19\end{array}$ \\
\hline Modificar & Sí & Sí & Sí \\
\hline
\end{tabular}




\begin{tabular}{|l|l|l|l|}
\hline $\begin{array}{l}\text { Mecanismos } \\
\text { de protección }\end{array}$ & $\begin{array}{l}\text { Sí. Dos. } \\
\text { Comisión } \\
\text { Interamericana de } \\
\text { Mujeres y Corte } \\
\text { Interamericana } \\
\text { de DDHH }\end{array}$ & $\begin{array}{l}\text { Sí. GREVIO. Fuera } \\
\text { de la competencia } \\
\text { del TEDH. }\end{array}$ & $\begin{array}{l}\text { Sí, Comité de } \\
\text { la CEDAW }\end{array}$ \\
\hline Reservas & $\begin{array}{l}\text { Permitidas con } \\
\text { límites abstractos }\end{array}$ & $\begin{array}{l}\text { Prohibidas salvo } \\
\text { disposiciones concretas }\end{array}$ & $\begin{array}{l}\text { Permitidas con } \\
\text { límites abstractos }\end{array}$ \\
\hline Enmienda & $\begin{array}{l}\text { Entran en vigor } \\
\text { cuando mayoría 2/3 }\end{array}$ & $\begin{array}{l}\text { Entran en vigor } \\
\text { cuando mayoría 2/3 }\end{array}$ & $\begin{array}{l}\text { Se prevé la } \\
\text { "revisión" } \\
\text { solicitándola al } \\
\text { Secretario General }\end{array}$ \\
\hline
\end{tabular}

Ambos textos regionales recogen la definición de "violencia contra la mujer" como uno de los problemas estructurales que impiden alcanzar la igualdad. La definición ofrecida por el Convenio de Estambul resulta algo más completa, incluyendo también un tipo de violencia económica que no recoge el texto americano. Cuestión, la de la feminización de la pobreza, que sí analiza separadamente la RG19 en relación al artículo 6 de la CEDAW.

Desde una perspectiva de los Derechos Humanos, es la Convención de Belén do Para la que ofrece una mayor sistematización al incorporar un catálogo de Derechos para las mujeres y también al incluir en su Preámbulo la declaración de que la violencia contra las mujeres constituye una violación de Derechos Humanos. Por otro lado, es el Convenio de Estambul el que, seguramente por ser el más moderno, establece un concepto de violencia más extendido, incluyendo en el mismo el ámbito familiar, el de la comunidad y el ámbito público o estatal. Pese a que esta amplitud pueda dar lugar a interpretaciones imprecisas ${ }^{48}$, esta es la línea que ha marcado en sus últimos informes el Comité de la CEDAW que reprendía precisamente a España por tener en su legislación interna un concepto demasiado limitado de "violencia de género"49. La RG19 incluye también en la definición de violencia la ejercida por las autoridades de un Estado, personas, organizaciones y/o empresas,

${ }^{48}$ Pérez Contreras, M. M., "Comentarios a la Convención Interamericana para prevenir, sancionar y erradicar la violencia contra la mujer: Convención Belén do Para”, Boletín Mexicano de Derecho Comparado, $n^{\circ} 95,1999$, pp. 667-679.

49 Hasta la fecha, España ha presentado un total de 8 informes periódicos al Comité para la Eliminación de la Discriminación de la Mujer. El último de ellos, elaborado en combinación con el séptimo y presentado en el año 2015, supone un avance con respecto a las recomendaciones ya establecidas por el Comité a la luz del sexto informe presentado en el año 2009, sobre todo gracias a la aprobación de diferentes instrumentos legislativos como la Ley Orgánica 1/2015 que modifica el Código Penal con respecto a la violencia contra la mujer o la Ley 12/2009 sobre asilo y protección subsidiaria que incluye el reconocimiento de la persecución de género en contextos de refugio y asilo (aunque con limitaciones).

Araucaria. Revista Iberoamericana de Filosofía, Política, Humanidades y Relaciones Internacionales, año 20, $\mathrm{n}^{\circ} 40$. Segundo semestre de 2018. Pp. 483-510. ISSN 1575-6823 e-ISSN 2340-2199 doi: 10.12795/araucaria.2018.i40.22 
siendo el Estado también responsable de la violencia perpetrada por actores privados. Como medidas concretas para prevenir la violencia se aboga por la protección efectiva de las víctimas, la capacitación de los funcionarios públicos, la eliminación de estereotipos por parte de los medios de comunicación, la capacitación y el acceso al empleo, oportunas y efectivas sanciones penales o la necesidad de elaborar programas de rehabilitación para los culpables. Desde esta perspectiva, el Comité de la CEDAW instaba así a España a completar la Ley 1/2004 de Medidas de Protección Integral contra la Violencia de género a fin de que incluyera otras formas de violencia además de la que ocurre en pareja, como la que sucede en el ámbito laboral, policial o la que ejercida por cuidadores u otros familiares ${ }^{50}$.

Otra de las razones por la que destaca la visión mucho más actual del Convenio de Estambul es su enfoque transfronterizo ${ }^{51}$ que lo hace incluir formas de violencia relacionadas con la delincuencia organizada trasnacional, como los matrimonios forzosos o la mutilación genital femenina. Asimismo, el Convenio dedica un capítulo a la migración y al asilo, haciéndose eco de las situaciones de violencia que sufren las mujeres en dichos escenarios e instando a que la violencia basada en el género sea considerada una forma de persecución en la interpretación de la Convención de Ginebra sobre el Estatuto de los Refugiados de 1951.

En todo caso, lo que más preocupa es el efectivo control por parte de los Estados de cumplimiento de las disposiciones establecidas en los textos. Es por ello que uno de los puntos más relevantes es el de los órganos de control. Es cierto que en el caso de la RG19 ésta vino motivada por la detección de informes incoherentes por parte de los Estados miembros, que según el Comité, no tomaban el asunto de la violencia con la debida interconexión de los elementos necesarios. Entre ellos, la violación de derechos fundamentales y libertades, la discriminación de género y, como consecuencia de éstas, la violencia. Por eso, el Comité de la CEDAW consideró necesario que los Estados parte tuvieran en cuenta en la elaboración de sus informes periódicos que esa violencia produce a su vez una anulación del goce en el ejercicio de los derechos fundamentales de las mujeres.. Será el Comité de la CEDAW el órgano receptor también de las denuncias o quejas presentadas por particulares, y también el encargado de controlar el cumplimiento general de los preceptos de la CEDAW y las Recomendaciones Generales.

En cuanto al Convenio de Estambul, es cierto que sólo se sostiene con un mecanismo de control no jurisdiccional y que no admite las denuncias

\footnotetext{
${ }^{50}$ Observaciones finales sobre los informes periódicos séptimo y octavo combinados de España, Comité para la Eliminación de la Discriminación contra la Mujer, 29 de julio de 2015. Párr. 8.

${ }^{51}$ Mercado Carmona, C., "La erradicación de la violencia contra la mujer "por Tratado": un análisis comparado del Convenio de Estambul y de la Convención de Belém do Pará", Revista Europea de Derechos Fundamentales, segundo semestre 2017, 30, pp. 213-239, p. 222.
} 
de particulares, GREVIO, que resulta bastante insuficiente por tener un enfoque bastante más cooperativo que sancionador, que tiene como objetivo fundamentalmente la prevención de la violencia ${ }^{52}$ hacia las mujeres a través del fomento de la tipificación y visibilización de ésta en los Estados parte. En cuanto a la Convención de Belém do Pará, su sistema de control es el más completo, al contar con la Comisión Interamericana de Mujeres, ante la que es posible que los particulares interpongan denuncias que, posteriormente, puede tomar en consideración la propia Corte Interamericana de Derechos Humanos, conjugando por tanto órganos de control no jurisdiccionales y jurisdiccionales.

\section{Tendencias jurisprudenciales en América Latina y Europa: CIDH y TEDH}

La protección de los Derechos Humanos de las mujeres se ha desarrollado fundamentalmente en los ámbitos regionales europeo y americano, además de en las resoluciones de las denuncias individuales del Comité de la CEDAW.

Por lo que respecta al TEDH, dado que como hemos tenido ocasión de comprobar, el Convenio de Estambul queda fuera de la competencia del Tribunal, su principal baluarte en cuanto a la defensa de la igualdad entre hombres y mujeres se encuentra en el artículo 14 del $\mathrm{CEDH}$, referido a la no discriminación, en este caso, por el motivo de sexo. Éste, tiene además un carácter dependiente ${ }^{53}$, por lo que siempre deberá ser alegado combinado con algún otro de los artículos del Convenio o los Protocolos Adicionales, normalmente el artículo 2 (Derecho a la vida), el 3 (Prohibición de la tortura) y, sobre todo, el artículo 8 (Derecho a la vida privada y familiar).

Hay que destacar que, pese a que pueda parecer contradictorio, ha sido el Tribunal de Justicia de la Unión Europea el que ha elaborado una jurisprudencia más extensa dentro del ámbito regional europeo sobre supuestos de discriminación por razón de sexo, tanto directa como indirecta, sobre todo en lo que tiene que ver con la desigualdad salarial, a través del artículo 157 TFUE ya desde principios de la década de los setenta. En el TEDH habría que esperar hasta el caso Abdulaziz, Cabales y Balkandali contra Reino Unido ${ }^{54}$ para aproximarnos a la primera sentencia estimatoria de una violación del artículo 14 por motivos de sexo $^{55}$ como discriminación directa. En esta ocasión el artículo 14 se alegaba en combinación con el artículo 8

\footnotetext{
${ }^{52}$ Gran, L., "The Istambul Convention and the Postive Obligation to Prevent Violence", Human Rights Law REview, 18, 2018, pp. 133-155.

53 Carmona Cuenca. E., "La igualdad de género en el Tribunal Europeo de Derechos Humanos", Revista Española de Derecho Constitucional, n 104, 2015, pp. 297-328, p. 307.

54 Asunto Abdulaziz, Cabales y Balkandali c. el Reino Unido, nº 21702/93.

${ }^{55}$ Carmona Cuenca, E., "La igualdad...op. cit.., p. 309.
} 
en un asunto de reagrupación familiar que Reino Unido había negado a tres mujeres inmigrantes cuando en la legislación interna si los peticionarios de esa reagrupación eran hombres sí que se permitía la reagrupación. Es cierto que el TEDH ha tenido una jurisprudencia sólida en cuanto al artículo 14 en la que ha admitido reiteradamente que aunque la legislación de un Estado pudiera incluir diferencias de trato entre sus ciudadanos, ésta no debe ser considerada automáticamente como discriminación. Por el contrario, el Tribunal admite ese diferente tratamiento siempre y cuando la medida legislativa en concreto tuviera una causa objetiva y razonable. En este caso, consideró que las razones de esa diferenciación normativa no eran suficientemente fuertes para encontrar justificación legal, dando la razón a las tres mujeres inmigrantes por considerar que se trataba de una medida legislativa discriminatoria por razón de sexo. El mismo criterio se repite en el caso Wessels-Bergervoet contra Holanda, al considerar una violación del artículo 14 en combinación en este caso con el artículo 1 por discriminación normativa en materia de pensiones. El Tribunal también encuentra una violación del artículo 14 en combinación con el artículo 8 en el caso Emel Boyraz contra Turquía ${ }^{56}$ apreciando una discriminación en el acceso por parte de una mujer a un puesto de trabajo como seguridad de una empresa pública que requería "ser hombre", pese a que la demandante había aprobado el examen necesario para tal desempeño y llevaba algunos años ya ejerciéndolo. Por eso, el tribunal ha sabido en muchos de los casos calibrar cuando una medida de diferenciación de trato ocasionaba realmente una discriminación directa por razón de sexo y, cuando se trataba de una medida objetivamente justificable sin que tuviera necesariamente que ocasionar una discriminación hacia las mujeres. Un tratamiento similar de la cláusula de no discriminación se ha producido también en el sistema interamericano. Por un lado, la Comisión seguía este criterio del TEDH a partir del año 2000 cuando establecía que "se espera un tratamiento equitativo de la ley para hombres y mujeres, a menos que se hayan aducido motivos justos, legitimos y razonables imperiosos para justificar una diferencia de tratamiento" 57.

Por otro lado, en el ámbito europeo la principal aportación del Protocolo Adicional $\mathrm{n}^{\circ} 12$ al CEDH al enfoque de la no discriminación, como comentábamos arriba, es que éste abre la puerta a la legitimación (y el fomento) del establecimiento de acciones positivas, sin que éstas tengan que suponer en sí mismas algún tipo de discriminación entre hombres y mujeres. Esta doctrina se comienza a aplicar en el caso Thlimmenos contra Grecia, donde el TEDH sigue la misma argumentación que había utilizado como requisito para que

\footnotetext{
${ }^{56}$ Caso Emel Boyraz contra Turquía, $\mathrm{n}^{\circ}$ 61960/08.

${ }^{57} \mathrm{CIDH}$, Consideraciones sobre la compatibilidad de las medidas de acción afirmativa concebidas para promover la participación política de la mujer con los principios de igualdad y no discriminación, en el Informe Anual de la CIDH 1999, OEA/Ser.L/V/II.106, dic. 3 rev., 13 de abril de 2000, capítulo VI, sección II, punto B.
} 
exista vulneración del artículo 14 en este caso por motivos de religión: puede haber diferenciación en el trato si hay una causa objetiva y razonable, y en este caso estima que para el establecimiento de una medida de discriminación positiva existía precisamente justa causa, pues su existencia era necesaria para garantizar la igualdad.

La doctrina Thlimmenos sigue su curso en el caso Stec y Otros contra Reino Unido ${ }^{58}$ relativo a la edad de jubilación (menor para las mujeres), alegando que existía una desigualdad fáctica que hacía necesaria dicha medida. Indudablemente, el Tribunal tiene el mismo criterio en aplicación del artículo 14 y del Protocolo Adicional $n^{\circ} 12$ basado en un planteamiento objetivo que dé es realmente lo que provoca la discriminación directa: la existencia de una norma o la ausencia de ella.

En el caso de las Niñas Yean y Bosico contra República Dominicana de la CIDH también se aprecia un seguimiento de esta argumentación. A las niñas, de origen haitiano, se les había negado la emisión de sus actas de nacimiento pese a haber nacido en el territorio del Estado (que se rige además por el ius soli) violando con ello su derecho a una nacionalidad, y obligándolas a permanecer apátridas durante toda su vida. La Corte estima en este asunto que "el principio de derecho imperativo de protección igualitaria y efectiva de la ley y no discriminación determina que los Estados, al regular los mecanismos de otorgamiento de la nacionalidad, deben abstenerse de producir regulaciones discriminatorias o que tengan efectos discriminatorios en los diferentes grupos de una población al momento de ejercer sus derechos. Además, los Estados deben combatir las prácticas discriminatorias en todos sus niveles, en especial en los órganos públicos, y finalmente debe adoptar las medidas afirmativas necesarias para asegurar una efectiva igualdad ante la ley de todas las personas" "59. La Corte Interamericana establece, así, la necesidad también adoptar medidas de discriminación positiva sin que esto suponga una violación de la cláusula general de no discriminación sino, en su caso una necesidad para cumplir con ella y fomentar la igualdad.

Fuera del ámbito del artículo 14 del CEDH, el TEDH ha tenido ocasión de pronunciarse sobre otras cuestiones que afectan directamente a las mujeres, como es el caso del aborto, a partir del caso Brüggemann y Scheuten contra la República Federal de Alemania en $1977^{60}$. En el aborto hay una pugna entre el derecho a la vida del feto (art. 2) y la libertad sobre el propio cuerpo de la madre en la que el Tribunal se ha decantado en la mayoría de ocasiones por la madre ${ }^{61}$.

\footnotetext{
${ }^{58}$ Caso Stec y Otros contra Reino Unido, no 65731/01 y 65900/01.

${ }^{59}$ Caso de las Niñas Yean y Bosico contra República Dominicana, Sentencia de 8 de septiembre de 2005, párr. 141 .

${ }^{60}$ Caso Brüggemann y Scheuten contra la República Federal de Alemania, no 6959/75.

${ }^{61}$ Consetino, C., "Safe and Legal Abortion: An Emerging Human Right? The Long-lasting Dispute with State Sovereignity in ECHR Jurisprudence", Human Rights Law Review, nº 15, 2005, pp. 569589 , p. 572.
}

Araucaria. Revista Iberoamericana de Filosofía, Política, Humanidades y Relaciones Internacionales, año 20, $\mathrm{n}^{\circ} 40$ Segundo semestre de 2018. Pp. 483-510. ISSN 1575-6823 e-ISSN 2340-2199 doi: 10.12795/araucaria.2018.i40.22 
En otros casos, el Tribunal ha tenido que pronunciarse sobre si prevalece el derecho del padre a decidir sobre su vida familiar y paternidad o, en su caso, la vida privada y familiar y el control sobre el propio cuerpo de la madre, decantándose de nuevo por la última, por ejemplo en Paton contra Reino Unido o R.H. contra Noruega. Sin embargo, el Tribunal no ha sido tan claro cuando la pugna tiene lugar entre el derecho de la madre a decidir sobre su propio cuerpo y, por otro lado, el Estado en su derecho de legislar sobre el aborto ${ }^{62}$. Es aquí donde la denominada doctrina del margen de apreciación de los Estados ha tenido más cancha para admitir que en el asunto del aborto intervienen factores morales, políticos y sociales sobre los que el Derecho Internacional no debe posicionarse por encima del interno siempre que la norma en cuestión cumpla unos requisitos mínimos: que haya existido un proceso de elaboración y adopción de dicha norma que sea democrático, la existencia de una práctica común de los Estados con respecto a la cuestión y la experiencia que ese Estado en particular alegue en la materia de que se trate ${ }^{63}$.

En el caso $A, B$ y $C$ contra Irlanda ${ }^{64}$ el Tribunal usó esta doctrina del margen de apreciación al legitimar la (hasta hace muy poco tiempo) fuertemente restrictiva regulación sobre el aborto en Irlanda ${ }^{65}$, considerando que éste era un ámbito en el que la acción y decisión de los Estados debía tener una fuerte consideración ${ }^{66}$ y por tanto estimando tan sólo la pretensión de $C$, que sí alegaba una de las pocas causas de aborto permitidas en la legislación irlandesa. Por su parte, las demandantes $A$ y $B$ alegaban motivos para abortar que no se incluían en la normativa irlandesa y, por tanto, no fue considerada la violación del artículo 8 .

Por el contrario, en la Corte Interamericana de Derechos Humanos también se han producido pronunciamientos sobre los derechos reproductivos de las mujeres, en concreto sobre el Derecho a recibir tratamientos de "fecundación in vitro" al amparo del artículo 8 sobre la vida privada y familiar. En la Sentencia de Artavia Murillo y otros (Fecundación in vitro) contra Costa Rica nos encontramos ante un conflicto también entre el derecho del Estado a legislar sobre la reproducción asistida y el derecho de la madre a decidir. La

${ }^{62}$ Ibídem.

${ }^{63}$ Arnardóttir, O. M., "The Differences that Make a Difference: Recent Developments on the Discriminations Grounds and the Margin of Appreciation under Article 14 if the European Convention on Human Rights", Human Rights Law Review, n 14, 2014, pp. 647-670.

${ }^{64}$ Caso A, B y C contra Irlanda, $\mathrm{n}^{\circ} 25579 / 05$.

65 Después del referéndum de 28 de mayo de 2018 sobre la derogación de la Octava enmienda a la Constitución del país que equiparaba la vida del feto a la de su madre (y por tanto, no existiendo Derecho al aborto), el Gobierno de Irlanda decidía despenalizar el aborto en las primeras 12 semanas sin que medie causa de justificación y hasta las 24 semanas de gestación cuando medie causa de justificación por primera vez en su historia.

${ }^{66}$ Al respecto Vid., Weinstein, 'Reproductive Choice in the Hands of the State: The Right to Abortion under the European Convention on Human Rights in Light of A, B \& C v. Ireland'American University International Law Review, n 27, 2012, p. 391.

Araucaria. Revista Iberoamericana de Filosofia, Politica, Humanidades y Relaciones Internacionales, año 20, $\mathrm{n}^{\circ} 40$ Segundo semestre de 2018. Pp. 483-510. ISSN 1575-6823 e-ISSN 2340-2199 doi: 10.12795/araucaria.2018.i40.22 
$\mathrm{CIDH}$ declaró inconstitucional un decretó que había promulgado Costa Rica ilegalizando esta práctica, considerando que el Estado era:

\begin{abstract}
"internacionalmente responsable por haber vulnerado los derechos a la vida privada y familiar y el derecho a la integridad personal en relación con la autonomía personal, el derecho a decidir si tener hijos bilógicos a través de una técnica de reproducción asistida, la salud sexual, el derecho a gozar de los beneficios del progreso científico y tecnológico, así como el principio de no discriminación"67.
\end{abstract}

Como se puede observar, en el ámbito interamericano ha prevalecido el derecho de la madre incluso sobre el derecho del Estado a legislar sobre las técnicas de reproducción asistida, mientras en el ámbito del TEDH la balanza se ha decantado por el Estado.

En la doctrina del margen de apreciación del TEDH hay elementos altamente preocupantes si consideramos que una de las razones que justifican su aplicación es que la norma haya sido adoptada en procesos democráticos pero, es evidente que existe un riesgo para el efectivo disfrute de los Derechos Humanos si concurriera una voluntad política contraria a ello (y no por ello formalmente anti democrática). Como se pregunta Cosentino "How far can a human rights Court consider evident social injustices legitimate on the basis of the free will of a population who supports them?"68.

Precisamente hay que notar que la doctrina del margen de apreciación de los Estados es perjudicial especialmente para los derechos humanos de las mujeres, que han estado tradicionalmente invisibilizado por las legislaciones de los Estados, y su discriminación se ha visto amparada en normas androcéntricas naturalizadas por los gobiernos y la sociedad. El TEDH se aparta aquí de la defensa y protección de derechos humanos del Convenio para proteger en exceso la soberanía de los Estados, cuestiones de orden moral mediante.

En cambio, otra de las doctrinas del TEDH que sí ha sido determinante en la protección de los derechos humanos de las mujeres y que ha sido seguida posteriormente por la Corte Interamericana de Derechos Humanos es la de la "diligencia debida". Es frecuente que la violencia que sufren las mujeres por el hecho de serlo no venga directamente de parte de un ente público como el Estado, sino que sea ejercida por actores no estatales que pueden ser muy próximos a la víctima. En el Derecho Internacional, y también en los Derechos Humanos, como afirma Miguel Juan "se ha tomado como persecución paradigmática la que sufre el varón en el ámbito público por parte de agentes estatales" ${ }^{69} \mathrm{y}$ se

${ }^{67}$ Caso Artavia Murillo y otros (Fecundación in vitro contra Costa Rica, Sentencia de 28 de noviembre de 2012, Serie C, $\mathrm{n}^{\circ} 257$, párr.. 317.

${ }^{68}$ Cosentino, C., "Safe and Legal..., op. cit., p. 576.

${ }^{69}$ Miguel Juan, C., Refugiadas. Una mirada feminista al Derecho Internacional, Catarata, 2016, pp. 269.

Araucaria. Revista Iberoamericana de Filosofía, Politica, Humanidades y Relaciones Internacionales, año 20, ${ }^{\circ} 40$. Segundo semestre de 2018. Pp. 483-510. ISSN 1575-6823 e-ISSN 2340-2199 doi: 10.12795/araucaria.2018.i40.22 
ha aplicado un principio de igualdad asimilacionista. En este sentido, quedaba por ver si hechos de violencia estructural ejercida por individuos quedaban impunes y desligaban al Estado de toda responsabilidad.

Pero la "diligencia debida" es una doctrina que encuentra su raíz en otros precedentes en órdenes jurisdiccionales internos ${ }^{70}$ y también en normas internacionales, como la Declaración sobre la eliminación de la violencia contra la mujer"1 que en su artículo 4.c) insta a los Estados a "proceder con la debida diligencia a fin de prevenir, investigar y, conforme a la legislación nacional, castigar todo acto de violencia contra la mujer, ya se trate de actos perpetrados por el Estado o por particulares". También las directrices establecidas por la Relatora Especial del Secretario General sobre la violencia contra la mujer de las Naciones Unidas contenían recomendaciones para los Estados a fin de que éstos tomaran medidas para cumplir efectivamente con este deber de diligencia ${ }^{72}$.

En el ámbito del TEDH, será a partir del asunto Jabarí contra Turquía $(2000)^{73}$ cuando el Alto Tribunal considere por primera vez que el Estado incurriría en una violación del artículo 3 del CEDH si la demandante fuera deportada a su país de origen, por considerar que corre grave riesgo su vida o integridad física, infligido éste por actores no estatales. En el supuesto, Jabari es acusada de cometer "adulterio" motivo por el cual corría un grave riesgo de ser apedreada en su país de origen, solicitando el asilo por esta razón (aunque fuera de plazo). El TEDH protege en virtud del artículo 3 del Convenio frente a una persecución por parte de actores no estatales que, en este caso, está fomentada y tolerada desde el propio Estado. El apedreamiento es una práctica dirigida hacia las mujeres que comporta violencia extrema y fuerte discriminación de género, por lo que se el TEDH, sirviéndose de una aplicación cautelar del artículo 3 (uno de los pocos artículos del Convenio que permite su aplicación preventiva) protege los Derechos Humanos de las mujeres por el hecho de serlo. En el ámbito interamericano la doctrina de la "diligencia debida" ya era recepcionada por la analizada Convención de Belem do Pará, que la incluye en su artículo 7 en el que los Estados parte se comprometen a "actuar con la debida diligencia para prevenir, investigar y sancionar la violencia contra la mujer", y que sería aplicada por primera vez en el caso Campo Algodonero contra México. En este paradigmático caso la CIDH consideró que el Estado era responsable de la falta de investigación de la desaparición de tres jóvenes con resultado de muerte en un entorno de violencia estructural por razón de género como es Ciudad

\footnotetext{
${ }^{70}$ Al respecto Vid., Jiménez Sánchez, C., "La persecución de género en el Derecho Internacional de los Refugiados: nuevas perspectivas", Revista Electrónica de Estudios Internacionales, $\mathrm{n}^{\circ}$ 33, 2017, pp. 1-31.

${ }_{71}$ Resolución 48/104 de la Asamblea General de las Naciones Unidas, de 20 de diciembre de 1993.

${ }^{72}$ Comisión de Derechos Humanos, E/CN.4/2003/75, de 6 de enero de 2003.

73 Asunto Jabari contra Turquía, no 4035/98.
} 
Juárez ${ }^{74}$. Este criterio supone una evolución del concepto de igualdad formal en el ámbito interamericano que ahora evoluciona hacia un concepto de igualdad material, que se relaciona con la noción de grupos socialmente subordinados y no se limita a la eliminación de privilegios discriminatorios ${ }^{75}$.

El TEDH también considera el asunto de la violencia contra las mujeres en el año 2008 en el asunto Bevacqua y S. contra Bulgaria ${ }^{76}$. La reclamante había solicitado el asilo amparándose en el artículo 8 del Convenio, en razón de la violencia que era ejercida por su marido de manera continuada hacia ella y hacia su hijo. El TEDH considera que el Estado es responsable de proteger la vida privada y familiar de Bevacqua, y que esta violencia escapa al concepto de "asunto privado", continuando con la doctrina de la "diligencia debida", y confirmando que el hecho de que sean actores no estatales los que ejercen directamente la violencia, el Estado no está exento de responsabilidad. La condena del Estado por la perpetración de violencia de género ejercida por la pareja de la víctima ha sido también la tendencia seguida por el Comité de la CEDAW, por ejemplo en el Dictamen González Carreño contra España, en el que el Estado es condenado por no haber protegido eficazmente a la víctima y a su hija, que fue finalmente asesinada por su padre durante el régimen de visitas (que se decretaron "no vigiladas"). El Comité considera que el elemento determinante del caso es considerar si las autoridades aplicaron principios de debida diligencia y tomaron medidas razonables con miras a proteger a la autora y su hija de posibles riesgos en una situación de violencia domestica continuada" "77.

De manera aún más directa se puede considerar la responsabilidad del Estado en el asunto Opuz contra Turquía (2009) ${ }^{78}$, en el que fue la pasividad de jueces y policías ante una violencia de género repetidamente denunciada y frente a la cual la demandante pidió auxilio en repetidas ocasiones. Finalmente, con resultado de muerte, el TEDH condena a Turquía por omisión de la protección de la víctima en virtud de los artículos 2 y 3 en combinación con el artículo 14. El TEDH consolida con la paradigmática Opuz contra Turquía la tendencia de condenar al Estado por no haber evitado los daños perpetrados por actores no estatales. En el mismo sentido, en el caso Campo Algodonero contra México ya aludido, de la Corte Interamericana de Derechos Humanos responsabiliza

\footnotetext{
${ }^{74}$ Caso González y Otras ("Campo Algodonero") vs. México, Sentencia de 16 de noviembre de 2009, (Excepción preliminar, Fondo, Reparaciones y Costas), Corte Interamericana de Derecho Humanos.

${ }^{75}$ Abramovich, V., "Responsabilidad estatal por violencia de género: comentarios sobre el caso "Campo Algodonero" en la Corte Interamericana de Derechos Humanos", Anuario de Derechos Humanos, 2010, pp. 167-182.

${ }^{76}$ Asunto Bevacqua y S. contra Bulgaria

${ }^{77}$ Comunicación núm. 47/2012, Dictamen adoptado por el Comité en su $58^{\circ}$ período de sesiones (30 de junio a 18 de julio de 2014).

${ }_{78}$ Asunto Opuz contra Turquía, no 33401/02.
} 
internacionalmente al Estado de manera parcial por la desaparición y muerte de tres jóvenes, ya que había incumplido su deber de investigar las desapariciones $\mathrm{y}$, con ello, se considera que ha atentado, entre otros, contra la vida, la integridad y libertad personales de las víctimas, pronunciamiento que también se produce en el caso Velázquez Rodríguez contra Honduras en el que se aprecia igualmente que el Estado tiene un deber jurídico de investigar de forma diligente y con la máxima prontitud las desapariciones para evitar la impunidad y la repetición de las violaciones de Derechos Humanos. Conclusiones muy similares ha seguido la Comisión Interamericana de Derechos Humanos en sus informes. En especial en el informe sobre Acceso a la Justicia de las Mujeres Victimas de Violencia en las Américas ${ }^{79}$ en el que la Comisión establece la necesidad de que los Estados investiguen con total diligencia y prontitud las desapariciones y las formas de violencia contra las mujeres, tanto la cometida por entes estatales como por actores no estatales.

Por lo que se refiere a violencia contra las mujeres fuera del ámbito de la pareja o familiar, es evidente que el liderazgo en los pronunciamientos lo ostenta la Corte Interamericana de Derechos Humanos, cuya competencia se extiende al citado texto Convención de Belem do Pará, mientras que en el ámbito europeo el Convenio de Estambul sobre violencia contra las mujeres queda fuera de la competencia del TEDH. La CIDH, además ha tenido ocasión de crear una interesante jurisprudencia sobre el propio concepto de violación, en el caso Rosenda Cantú y Otra contra México. Cantú, mujer indígena que vivía en un estado donde imperaba una situación de guerra fue violada por dos militares cuando se encontraba cerca de un arroyo. La Corte tiene aquí la oportunidad de seguir la jurisprudencia de los Tribunales Penales Internacionales sobre el concepto de violación, considerando que "la violencia sexual se configura con acciones de naturaleza sexual que se cometen contra una persona sin su consentimiento, que además de comprender la invasión física del cuerpo humano, pueden incluir actos que no involucren penetración o incluso contacto físico alguno. En particular, la violación sexual constituye una forma paradigmática de violencia contra las mujeres cuyas consecuencias, incluso, trascienden a la persona de la víctima". De hecho, uno de los elementos más innovadores del caso Algodonero es el de calificar la violencia sufrida por las tres víctimas como violencia basada en el género, delimitada en el artículo 1 de la Convención de Belem do Pará, añadiendo, además, que los hechos eran constitutivos de "feminicidio" al que define como "homicidio de mujeres en razón de género" 80 , incorporando por primera vez este concepto en una sentencia de un tribunal internacional. Pese a que el TEDH también

\footnotetext{
${ }^{79} \mathrm{CIDH}$, Acceso a la Justicia para Mujeres Víctimas de Violencia en las Américas, OEA/Ser.L/V/ II., Doc. 68, 20 de enero de 2007.

${ }^{80}$ Caso González y Otras...,op. cit, párr. 143.
} 
se pronuncia, como hemos visto, sobre supuesto de violencia de género, es más reacio a entrar en los conceptos más progresistas usados en el ámbito interamericano, como el de feminicidio o el de violación, pese a que en este último el Convenio de Estambul fija los mismos criterios en torno a la ausencia de consentimiento que el resto de normas y jurisprudencia internacional penal.

Igualmente restrictivo ha sido el TEDH en supuestos en los que intervienen elementos de diversidad cultural. En alegación del artículo 3 del CEDH se ha estudiado en el ámbito europeo la protección a las mujeres de la Mutilación Genital Femenina (MGF) ${ }^{81}$ en los asuntos Izebekhai contra Irlanda (2011), Omeredo contra Austria (2011) y el asunto Sow contra Bélgica (2016), con la imposición de medidas cautelares que impidieran el traslado de las denunciantes a su país de origen por existir un grave riesgo de que las MTG fueran llevadas a cabo. Sin embargo, todos los casos fueron finalmente inadmitidos por falta de pruebas. Hay otras situaciones que también podrían acarrear una violación del artículo 3 , el grave riesgo de sufrir tratos inhumanos o degradantes y el peligro de sufrir un asesinato de honor que han resultado probatoriamente menos complejos que la MTG para el TEDH $^{82}$. Ocurrió así en el asunto R. D. Contra Francia (2016) en el que el TEDH sí encuentra una posible violación del artículo 3 si la demandante viajara a su país de origen, aplicándolo de nuevo de manera preventiva. Sin embargo, esta tendencia que se incia en Jabari contra Turquía y continua hasta $R$. D. Contra Francia, no es uniforme. Existe otros casos en los que el Alto Tribunal ha desestimado la aplicación preventiva del artículo 3 pese a existir claros indicios de persecución de género y grave riesgo para la integridad física y la propia vida, así como de sufrir práctica de género discriminatorias como la MTG o el matrimonio forzado, por ejemplo en N. Contra Reino Unido (2008) o AA contra Suecia (2012).

Por último, otro de los ámbitos en los que ha destacado el ámbito interamericano ha sido en el de las reparaciones. Este camino se inicia con el caso Campo Algodonero contra México, estableciendo en concordancia con la Convención Americana de Derechos Humanos una tendencia hacia la reparación de las mujeres por parte del Estado cuando éste ha sido condenado como responsable o parcialmente responsable. En esta sentencia se establecen formas de reparación concretas, como la obligación de conducir una investigación eficaz sobre lo ocurrido. También en la CIDH es donde el Estado Guatemalteco ha sido constreñido a otorgar reparaciones materiales a mujeres (Klée \& Artigas, 2001), además de medidas de dignificación de la memoria, atención psicológica o estrategias de prevención en casos como Marco Molina Theissen, Bámaca Velásquez o Maritza Urrutia.

\footnotetext{
${ }^{81}$ Miguel Juan, C., "La mutilación genital femenina, derecho de asilo en España y otras formas de protección internacional", The Aire Centre.

${ }^{82}$ Morgades Gil, S., "La protection internationale des femmes pour des raisons liées au genre en droit international. Interprétations récentes des instruments de droit international soutenant des formes de protection subsidiaire", Revue Generale de droit international public, vol. 117, nº 1, 2013, pp. 37-73. 


\section{Conclusiones}

Los ámbitos regionales europeo y americano son líderes en la protección de los derechos humanos de las mujeres, en seguimiento del espíritu de las normas universales de protección, esencialmente la CEDAW. No obstante, los textos regionales de protección de derechos humanos de las mujeres resultan insuficientes, especialmente en el ámbito europeo en el que el Convenio de Estambul no recoge ningún catálogo de derechos humanos de las mujeres y niñas.

En ambos sistemas, ha tenido prevalencia la adopción de textos contra la violencia contra las mujeres por encima de los catálogos de Derechos Humanos. Tanto la Convención de Belem do Pará como el Convenio de Estambul son ejemplos altamente relevantes de la conceptualización sistemática de la violencia contra las mujeres que se produce en todos los ámbitos de la vida pública y privada, destacando la inclusión en ambos textos de la doctrina de la "diligencia debida" por parte de los Estados como garantes de los derechos humanos y responsables de las acciones y omisiones que puedan producir situaciones de violencia y peligro para las mujeres.

El ejemplo del TEDH y la CIDH son una muestra de cómo los tribunales internacionales de Derecho Humanos pueden establecer responsabilidad hacia el Estado por los actos cometidos por actores no estatales, también cuando se trata de violencia hacia las mujeres y de otras prácticas discriminatorias por razón de género.

En cuanto a las doctrinas seguidas por el TEDH, hay que reiterar que la referida al "margen de apreciación de los Estados" es altamente perjudicial para los derechos humanos de las mujeres, que pueden quedar desprotegidas por el Alto Tribunal aun cuando exista vulneración sus derechos en la legislación nacional. El TEDH aquí ha dado prioridad al respeto a la soberanía de los Estados por encima de a los derechos humanos, por lo que su liderazgo en este campo queda en entredicho.

Por el contrario, la doctrina de la diligencia debida iniciada en Jabari contra Turquía es positiva y necesaria para la protección de las mujeres, que normalmente sufren la violencia por parte de actores no estatales en marcos estructurales de discriminación social y familiar. La consagración de esta doctrina por parte del TEDH ha supuesto una influencia muy valiosa en otros tribunales nacionales e internacionales.

Tenemos, por tanto, que el Alto Tribunal europeo puede utilizar dos varas de medir según el caso concreto en cuanto a la igualdad de género, lo que fomenta que su práctica en este tema no sea uniforme y que existan pronunciamientos contradictorios en su jurisprudencia.

La Corte Interamericana de Derechos Humanos sigue la doctrina de la diligencia debida, por lo que se han producido pronunciamientos muy valiosos 
relativos a diferentes ámbitos de la vida de las mujeres. Igualmente, hay que destacar que la Convención de Belem do Pará sí se enmarca dentro de la competencia de la Corte y que, por tanto, su protección de los derechos humanos de las mujeres y frente a la violencia es más completa y eficaz. Igualmente, ha sido más progresista en la elaboración de conceptos como violación o feminicidio, situándose como el relevo del TEDH en el liderazgo de la comprensión de los derechos humanos de las mujeres. 


\section{Referencia bibliográficas:}

Abramovich, V., "Responsabilidad estatal por violencia de género: comentarios sobre el caso "Campo Algodonero" en la Corte Interamericana de Derechos Humanos", Anuario de Derechos Humanos, 2010, pp. 167-182.

Acosta López, J. I.; Luque Vallejo, A M., "Declaración Universal de Derechos Humanos, ¿norma de ius cogens?”, International Law: Revista colombiana de Derecho Internacional, $\mathrm{n}^{\mathrm{o}} 12,2008$, pp. 13-34.

Arnardóttir, O. M., "The Differences that Make a Difference: Recent Developments on the Discriminations Grounds and the Margin of Appreciation under Article 14 if the European Convention on Human Rights", Human Rights Law Review, no 14, 2014, pp. 647-670.

Barranco Avilés, $M^{\mathrm{a}}$. del C., "El enfoque feminista de los derechos fundamentales desde la perspectiva de género", en Género y Derechos Fundamentales, (Monereo Atienza, C.; Monereo Pérez, J. L., coords.), Granada, Comares, pp. 49-85.

Brysk, A., "Introducción: violencia de género y Relaciones Internacionales", Revista CIBOD D'afers Interacionals, $\mathrm{n}^{\circ}$ 117, 2017, pp. 7-28.

Cançado Trindade, A. A., "International Law for Humankind: Towards a New Jus Gentium", 317 R. des Cours, 2005, pp. 536.

Carmona Cuenca, E., "La igualdad de género en el Tribunal Europeo de Derechos Humanos", Revista Española de Derecho Constitucional, ${ }^{\circ}$ 104, 2015, pp. 297-328.

Carrillo Salcedo, J. A., Soberanía del Estado y Derechos Humanos en el Derecho Internacional Contemporáneo, Tecnos, 2001, Madrid, pp. 186.

Charlesworht, H.; Chinkin, C., The Boundaries of International Law. A feminist analysis, Meland Schill Studies in International Law, Juis Publishing, Manchester University Press, Manchester, 2000, pp. 414.

Consetino, C., "Safe and Legal Abortion: An Emerging Human Right? The Long-lasting Dispute with State Sovereignity in ECHR Jurisprudence", Human Rights Law Review, $\mathrm{n}^{\circ}$ 15, 2005, pp. 569-589.

Gran, L., "The Istambul Convention and the Postive Obligation to Prevent Violence", Human Rights Law REview, 18, 2018, pp. 133-155.

Jiménez Sánchez, C., "La persecución de género en el Derecho Internacional de los Refugiados: nuevas perspectivas", Revista Electrónica de Estudios Internacionales, $\mathrm{n}^{\circ} 33,2017$, pp. 1-31.

Maquieira, V., "Mujeres, globalización y derechos humanos", en Mujeres, globalización y Derechos Humanos, Maqueieira, V. (Ed.), pp. 33-87, p. 68, $1^{\text {a }}$ edición, Ediciones Cátedra, 2006, Valencia, pp. 405. 
Martín Martínez, M. y Jiménez Sánchez, C., "La protección internacional de los derechos humanos de las mujeres: una visión desde la multiculturalidad y la perspectiva de género", en Diversidad Cultural, Género y Derecho, (Laurenzo Copelo, P.; Durán Muñoz, R., Coords.), Tirant lo Blanch, Valencia, 2013, pp. 271-307.

Mercado Carmona, C., "La erradicación de la violencia contra la mujer "por Tratado": un análisis comparado del Convenio de Estambul y de la Convención de Belém do Pará", Revista Europea de Derechos Fundamentales, segundo semestre 2017, 30, pp. 213-239.

Meron, T., "International Law in the age of Human Rights", 301 Recueil des Cours, 2003, pp. 489.

Miguel Juan, C., "La mutilación genital femenina, derecho de asilo en España y otras formas de protección internacional", The Aire Centre.

Miguel Juan, C., Refugiadas. Una mirada feminista al Derecho Internacional, Catarata, 2016, pp. 269.

Morgades Gil, S., "La protection internationale des femmes pour des raisons liées au genre en droit international. Interprétations récentes des instruments de droit international soutenant des formes de protection subsidiaire", Revue Generale de droit international public, vol. 117, $\mathrm{n}^{\circ}$ 1, 2013, pp. 37-73.

Pérez Contreras, M. M., "Comentarios a la Convención Interamericana para prevenir, sancionar y erradicar la violencia contra la mujer: Convención Belén do Para", Boletín Mexicano de Derecho Comparado, nº 95, 1999, pp. 667-679.

Robertson, A. H., "Humanitarian Law and Human Rights", en Studies and essays on international humanitarian law and Red Cross principles in honour of Jean Pictet, Swinarski, C (ed.), CICR/Martinus, Ginebra/La Haya, 1984, pp. 793-802.

Simonovic, D., "Global and Regional Standarts on Violence Against Women: The Evolution and Sinergy of the CEDAW and Istambul Conventions", Human Rights Quarterly, 36 (2014), pp. 590-606.

Weinstein, 'Reproductive Choice in the Hands of the State: The Right to Abortion under the European Convention on Human Rights in Light of $\mathrm{A}, \mathrm{B} \& \mathrm{C}$ v. Ireland' American University International Law Review, $\mathrm{n}^{\mathrm{o}}$ 27, 2012. 